\title{
Complexation Reactions in a Heterogeneous System
}

\author{
CHUEN-YING LIU*, HUAN-TSUNG CHANG and CHO-CHUN HU \\ Department of Chemistry, National Taiwan University, Taipei (Taiwan) \\ (Received September 28, 1989)
}

\begin{abstract}
A new resin incorporating the $N$-(hydroxymethyl)thioamide group anchored on macroreticular acrylonitrile-divinylbenzene copolymer was described. The dissociation constant of the functional group of this resin, $\mathrm{p} K_{\mathrm{a}}$ was 6.56. Elementary analysis, infrared spectra and some chemical reactions were used for characterization. The optimum $\mathrm{pH}$ for $\mathrm{Ag}(\mathrm{I}), \mathrm{Cd}(\mathrm{II})$, $\mathrm{Co}(\mathrm{II}), \mathrm{Cu}(\mathrm{II}), \mathrm{Fe}(\mathrm{III}), \mathrm{Hg}(\mathrm{II}), \mathrm{Ni}(\mathrm{II}), \mathrm{Pb}(\mathrm{II})$ and $\mathrm{Zn}$ (II) ion complexation and the stability constants of cadmium, copper and silver resin complexes were also determined. The affinity of these metal ions toward the synthesized resin was in the order of $\mathrm{Hg}(\mathrm{II})>\mathrm{Fe}(\mathrm{III})>\mathrm{Pb}(\mathrm{II})>\mathrm{Cu}(\mathrm{II})>\mathrm{Cd}$ (II) $>\mathrm{Co}$ (II) $>\mathrm{Ni}$ (II) $\geqslant \mathrm{Zn}$ (II) on the basis of $\mathrm{pH}_{1 / 2}$ which is the $\mathrm{pH}$ for $50 \%$ sorption of metal ions on the resin. All the cations in the resin-metal kinetics study showed high exchange rates except that for iron which required seven min.
\end{abstract}

\section{Introduction}

Hydroxamic acids have been known for over a century and have been found useful in numerous applications $[1,2]$. They have been widely used as reagents in spectrophotometry, as precipitating agents in gravimetric analysis and as metallochromic indicators. There are many review articles on the chemistry of the hydroxamic acids [3-5]. However, the corresponding sulfur compounds (thiohydroxamic acids), because of their instabilities and difficulties of synthesis, are dealt with only peripherally. Substitution of a sulfur donor for an oxygen donor would be expected to result in changes in reagent behavior and an increased selectivity toward the noble and heavy metals than to the oxygen donor. The metal chelates and the parent acid all show potential antibiotic activity. Very little work appears to have been carried out on the chelating behavior of thiohydroxamic acids [6-9] and, needless to say, the further incorporation of the thiohydroxamic acid

*Author to whom correspondence shouid be addressed. functional group into the polymer matrix to give the chelating resin. In previous studies, we have synthesized chelating resins containing the functional groups, hydroxamic acid (-CONHOH) [10] and thiohydroxamic acid $(-\mathrm{CSNHOH})[11]$. In this investigation, we will synthesize a resin containing the functional group of another kind of thiohydroxamic acid $N$-(hydroxymethyl)thioamide $\quad\left(-\mathrm{CSNHCH}_{2} \mathrm{OH}\right)$, which will form a six membered chelating ring with the metal ions; - CSNHOH forms a five membered chelating ring with the metal ions. The aim of the present investigation is to study the complexing behavior of the synthesized chelating resin with some metal ions. The work gives fundamental information on their use as agents for heavy metal and noble metal ions separation and recovery in solution, or as a stationary phase of ligand exchange chromatography.

\section{Experimental}

\section{Spectroscopic Measurements}

IR spectra of the $N$-(hydroxymethyl)thioamide chelating resin and its metal complexes were obtained on a Bomem DA 3.02 infrared spectrophotometer using $\mathrm{KBr}$ pellets.

\section{Synthesis of the N-(Hydroxymethyl)thioamide Chelating Resin}

A macroporous cross-linked copolymer was prepared by the reaction of acrylonitrile and divinylbenzene by the procedure given in ref. 12. A one liter round bottomed flask equipped with a mechanical stirrer, reflux condenser, thermometer and an inlet tube for nitrogen gas was charged with $450 \mathrm{ml}$ of dioxane, then $25 \mathrm{ml}$ of concentrated sulfuric acid and $20 \mathrm{~g}$ of thioacetamide were added. After stirring under nitrogen for $10 \mathrm{~min}, 30 \mathrm{~g}$ of the above product (acrylonitrile-divinylbenzene copolymer) was added. The mixture was reacted at $90{ }^{\circ} \mathrm{C}$ for $48 \mathrm{~h}$. The product I was collected by filtration under suction and washed sequentially with water, methanol and acetone. Product I was mixed with $220 \mathrm{ml}$ formaldehyde. Then $6.5 \mathrm{ml}$ of $2 \mathrm{M} \mathrm{NaOH}$ were added dropwise and the mixture was left to react at $45{ }^{\circ} \mathrm{C}$ 
for $24 \mathrm{~h}$. The product was collected by suction filtration and washed sequentially with methanol, acetone and water. The product was immersed in $500 \mathrm{ml}$ of $0.1 \mathrm{M} \mathrm{NaCl}$ for $24 \mathrm{~h}$. The obtained product was washed free of chloride with water.

The reaction steps were as follows:

acrylonitrile + divinylbenzene $\stackrel{\alpha, \alpha \text {-azobisisobutyronitrile }}{\longrightarrow}$

Sodium lauryl sulfate

$\mathrm{NaCl} \longrightarrow$ Copolymer $(\mathrm{R}-\mathrm{C} \equiv \mathrm{N})$

$\mathrm{R}-\mathrm{C} \equiv \mathrm{N}+\mathrm{CH}_{3} \underset{\mathrm{S}}{\mathrm{CNH}_{2}} \frac{\mathrm{H}^{+}}{\text {dioxane, } 90^{\circ} \mathrm{C}}$<smiles>[R2]C[CH+]C#N</smiles>

Product I

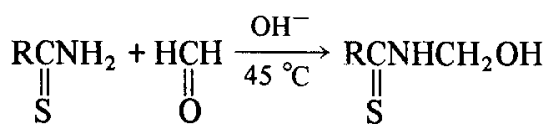

\section{Determination of the Dissociation Constant of the Resin}

Various amounts of $0.100 \mathrm{~mol} / 1$ sodium hydroxide were added to each $0.2 \mathrm{~g}$ resin sample. The ionic strength of $1.0 \mathrm{~mol} / 1$ and the $25 \mathrm{ml}$ final volume were adjusted by the addition of a calculated quantity of $2.5 \mathrm{~mol} / \mathrm{l}$ sodium chloride and water. The system was left to equilibrate for two days at $25^{\circ} \mathrm{C}$. Then, the $\mathrm{pH}$ of the solution phase was measured and some of the other parameters were determined as follows.

\section{Determination of the amount of counterions in} the resin phase

The sodium ions were eluted from the resin with $20 \mathrm{ml}$ of $0.1 \mathrm{~mol} / 1$ nitric acid and collected in a $50 \mathrm{ml}$ volumetric flask. The resin was washed free of chloride with water and the solution made up to the mark. The amount of chemically bound sodium ions was obtained by titration of the acid left in the solution, with $0.1 \mathrm{~mol} / 1$ sodium hydroxide and that of the invasive sodium chloride by a Volhard method determination.

\section{Determination of the hydrogen ion capacity}

To obtain the hydrogen ion capacity, the amount of chemically bound counter ions was plotted against the $\mathrm{pH}$ of the resin phase.

\section{Optimum $\mathrm{pH}$ for Metal Ion Complexation}

$\mathrm{pH}$ dependence of metal ion capacity and trace metal ion uptake of the $N$-(hydroxymethyl)thioamide resin were evaluated as previously by a batch equili- bration technique [11]. Bricfly, metal ion was loaded on $0.3 \mathrm{~g}$ of resin. After equilibration, the solid was filtered off and washed with water. The amount of metal ion in the filtrate was determined titrimetrically or spectrophotometrically.

\section{Determination of the Formation Constants}

For determination of the formation constants, three kinds of method were used in this study.

(1) The formation constants were determined by using the $100 \mathrm{ml}$ PE bottle charged with $0.3 \mathrm{~g}$ of airdried resin. To each bottle were added different amounts of $0.1 \mathrm{M}$ metal perchlorate solution and $4 \mathrm{ml}$ of $2.5 \mathrm{M}$ potassium chloride was added to make the total volume of solution of $50 \mathrm{ml}$. After equilibration for $72 \mathrm{~h}$, the liquid was separated from the resin, and the metal ion in the filtrate was determined and the extent of swelling of the resin was also determined. Simultaneously $\mathrm{pH}$ measurements were made on the filtrate.

(2) Different quantilies of air-dried resin in the hydrogen form were placed in $100 \mathrm{ml}$ PE bottles. To each bottle were added $50 \mathrm{ml}$ of solution containing varying amounts of metal ions and varying quantities of the external complexing ligands, EDTA. After an equilibration period of three days, the $\mathrm{pH}$ of the solution was measured and the quantity of metal ion remaining in the solution was determined spectrophotometrically.

(3) An air-dried resin was weighed into an ionexchange column (120 $55 \mathrm{~mm}$ i.d.). The column was conditioned with $\mathrm{pH} 6.0,1 \mathrm{M}$ acetic acid-sodium acetate buffer. Then, $0.1 \mathrm{mmol}$ cadmium ion was applied on the top of the column. The metal ion adsorbed was then eluted with $0.01 \mathrm{M}$ hydrochloric acid and $1.5 \mathrm{ml}$ fractions of the effluent were collected. The $\mathrm{pH}$ was measured and the metal ion content in each fraction was determined spectrophotometrically.

\section{Results and Discussion}

\section{Characterization of the $N-(H y d r o x y m e t h y l)$ thioamide Chelating Resin}

In order to elucidate the structure of the synthesized chelating resin, the infrared spectra obtained with $\mathrm{KBr}$ pellets were recorded after each step in the synthesis. Figure 1(a) is the spectrum of the acrylonitrile-divinylbenzene copolymer, which shows two characteristic absorption bands at $2240(-\mathrm{C} \equiv \mathrm{N})$ and $1600(-\mathrm{Ar}) \mathrm{cm}^{-1}$. Figure $1(\mathrm{~b})$ is the spectrum of the intermediate substance; if the reaction was completed, the absorption band attributed to the $-\mathrm{C} \equiv \mathrm{N}$ group should disappear. Since there is still a band at $2240 \mathrm{~cm}^{-1}$, the results of the IR spectra are, thus, indicative of the presence of the unreacted $-\mathrm{C} \equiv \mathrm{N}$ group. The prominent band, $\mathrm{NH}$ of $-\mathrm{CSNH}$, 


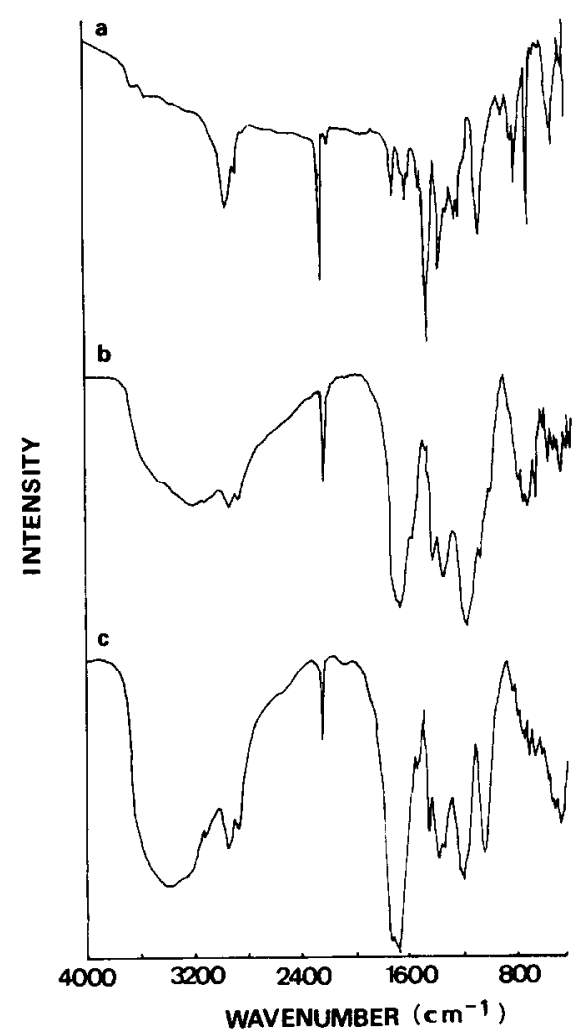

Fig. 1. Infrared spectra (a) acrylonitrile-divinylbenzene copolymer, (b) the intermediate substance, (c) $N$-(hydroxymethyl)thioamide resin.

appears at 3300,1674 and $1527 \mathrm{~cm}^{-1}$, which is in accordance with the spectrum of monomeric thioacetamide [13].

Figure 1(c) is the spectrum of the final product which shows characteristic absorption bands of $-\mathrm{OH}$ at $1048 \mathrm{~cm}^{-1}$ and a broader band at $3300 \mathrm{~cm}^{-1}$. The results indicate the presence of the $N$-(hydroxymethyl)thioamide group in the synthesized resin. The composition of the synthesized chelating resin was also confirmed by elementary analysis. The nitrogen content of the copolymer was $22 \%$ indicating the presence of the $-\mathrm{CN}$ group. The nitrogen content of the final product was $11.25 \%$, indicating that some of the $-\mathrm{CN}$ group was converted into $-\mathrm{CSNHCH}_{2} \mathrm{OH}$. However, the sulfur content was only $1.37 \%$ indicating the presence of some unreacted $-\mathrm{CN}$ group. The result of the sulfur content corresponds to $0.43 \mathrm{mmol}$ of $N$-(hydroxymethyl)thioamide per gram of resin.

For evaluation of the dissociation constant of the synthesized chelating resin, some parameters, such as $\bar{\alpha}^{*}, G_{\mathrm{K}}, G_{\mathrm{I}},[G],[H],[\bar{H}], Q$ and $\overline{\mathrm{H}_{2} \mathrm{O}}$, should be established [14], where $\bar{\alpha}^{*}$ : the mole fraction of the non-protonated base in the resin phase, $G_{\mathbf{K}}$ : the amount of chemically bound counter ion, $G_{\mathbf{I}}$ : the amount of ions migrated into the resin lattice,

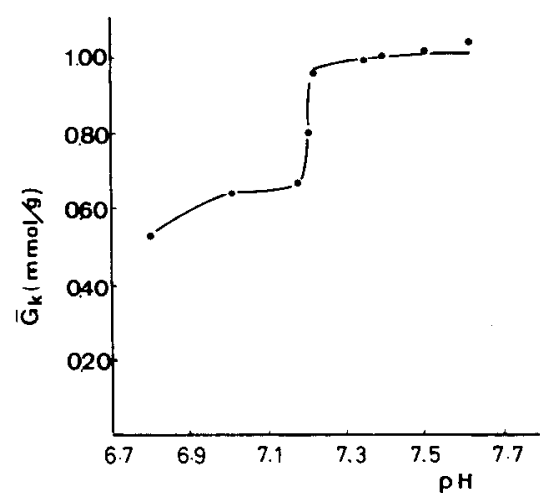

Fig. 2. Determination of the hydrogen content of the $N$-(hydroxymethyl)thioamide resin.

TABLE 1. Determination of the dissociation constant of the $N$-(hydroxymethyl)thioamide resin ${ }^{a}$

\begin{tabular}{cccccccc}
\hline $\mathrm{pII}$ & $\overline{\mathrm{I}_{2} \mathrm{O}}$ & $\bar{G}_{\mathrm{K}}$ & $\bar{G}_{\mathbf{1}}$ & $(G)$ & $\mathrm{pH}$ & $\bar{\alpha}^{*}$ & $\mathrm{p} K_{\mathrm{a}}$ \\
\hline 6.80 & 0.54 & 0.53 & 0.33 & 1.59 & 6.72 & 0.53 & 6.67 \\
7.01 & 0.49 & 0.65 & 0.35 & 2.04 & 6.83 & 0.65 & 6.56 \\
7.19 & 0.52 & 0.72 & 0.36 & 2.08 & 7.00 & 0.72 & 6.60 \\
7.20 & 0.59 & 0.80 & 0.39 & 2.00 & 7.01 & 0.80 & 6.40 \\
\hline
\end{tabular}

aVolume of solution: $25 \mathrm{ml}$, amount of resin: $0.3 \mathrm{~g}$, ionic strength: $1.33 \mathrm{M}$, temperature: $25^{\circ} \mathrm{C}$.

$[G]$ : the concentration of the counter ions in the resin phase, $[H]$ : the proton activity in the solution phase, $[\bar{H}]$ : the proton activity in the resin phase, $Q$ : the hydrogen capacity of the resin, $\overline{\mathrm{H}_{2} \mathrm{O}}$ : the water content of the resin.

The water regain of the resin determined by the method of centrifuging [10] was $0.57 \mathrm{~g} \mathrm{~g}^{-1}$. The plot of $G_{\mathrm{K}}$ versus $\mathrm{pH}$ (Fig. 2) showed that the hydrogen

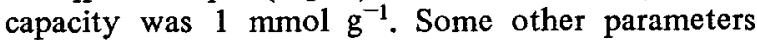
determined are listed in Table 1. From this Table, the dissociation constant of the resin could be calculated [14]. Due to the steric hindrance of the polymer matrix, the $\mathrm{p} K_{\mathrm{a}}$ of the synthesized resin, 6.56 , is rational in comparison with that of the monomeric thiohydroxamic acid [15] and thioacetamide [16], $5 \sim 8$.

\section{Complex Formation of the N-(Hydroxymethyl)- thioamide Chelating Resin}

The coloration development of the $N$-(hydroxymethyl)thioamide resin after treatment with excess metal ions is shown in Table 2. Since there was a large variation in coloration, the results showed that complex formation must occur between the metal ion and the synthesized resin.

The complex formation of the synthesized resin in the presence of excess amounts of $\mathrm{Ag}(\mathrm{I}), \mathrm{Cd}(\mathrm{II})$, $\mathrm{Co}(\mathrm{II}), \mathrm{Cu}(\mathrm{II}), \mathrm{Fe}$ (III), $\mathrm{Hg}(\mathrm{II}), \mathrm{Ni}$ (II), $\mathrm{Pb}$ (II) and $\mathrm{Zn}(\mathrm{II})$ were measured at various $\mathrm{pII}$ values and the 
TABLE 2. Coloration development of the $N$-(hydroxymethyl)thioamide resin in the presence of excess metal ions

\begin{tabular}{ll}
\hline Metal ion & Color \\
\hline & pale orange \\
$\mathrm{Ag}(\mathrm{I})(\mathrm{pH}<2)$ & white \\
$\mathrm{Ag}(\mathrm{I})(\mathrm{pH}>2)$ & reddish orange \\
$\mathrm{Au}(\mathrm{III})(\mathrm{pH}<2)$ & pale grey \\
$\mathrm{Au}(\mathrm{III})(\mathrm{pH}>2)$ & yellow \\
$\mathrm{Au}(\mathrm{III})($ in presencc of $\mathrm{HBr})$ & reddish orange \\
$\mathrm{Au}(\mathrm{III})\left(\right.$ in presence of $\left.\mathrm{Br}_{2}\right)$ & purple \\
$\mathrm{Cd}(\mathrm{II})$ & pale orange \\
$\mathrm{Co}(\mathrm{II})$ & pink \\
$\mathrm{Cu}(\mathrm{II})\left(\right.$ in excess of $\left.\mathrm{NH}_{3}\right)$ & brown \\
$\mathrm{Cu}(\mathrm{II})$ & greenish blue \\
$\mathrm{Hg}(\mathrm{II})$ & white \\
$\mathrm{Ni}(\mathrm{II})$ & pale orange \\
$\mathrm{Pb}(\mathrm{II})$ & pale orange \\
$\mathrm{Pt}(\mathrm{IV})$ & orange \\
$\mathrm{Zn}(\mathrm{II})$ & pale orange \\
\hline
\end{tabular}
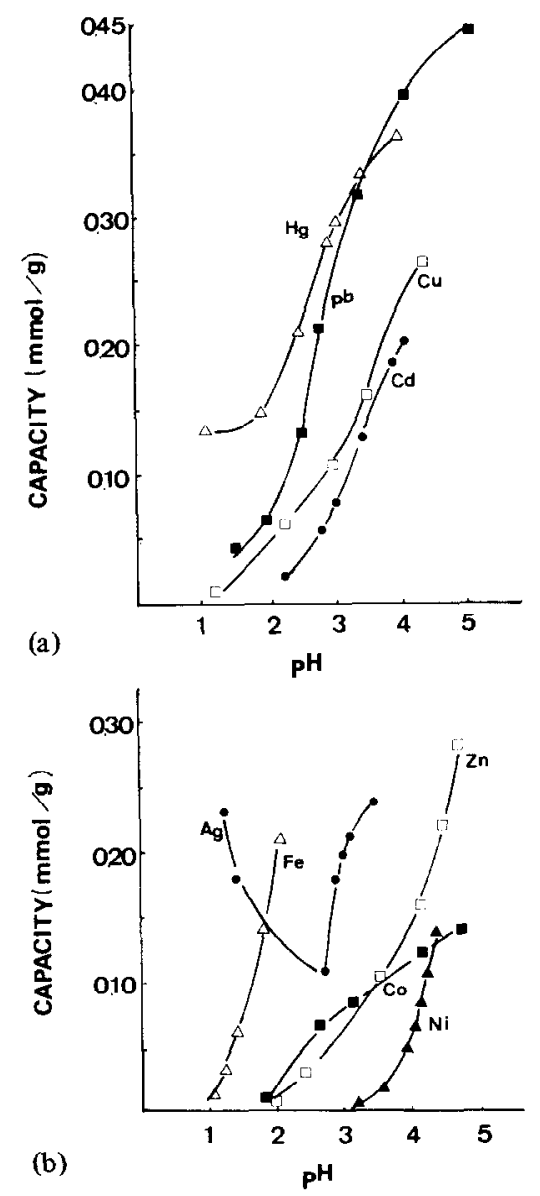

Fig. 3. Metal capacity as a function of $\mathrm{pH}$.

results are given in Fig. 3(a) and (b). Most of the metal ions showed greater capacity as the $\mathrm{pH}$ of the solution increased. The capacily of the synthesized

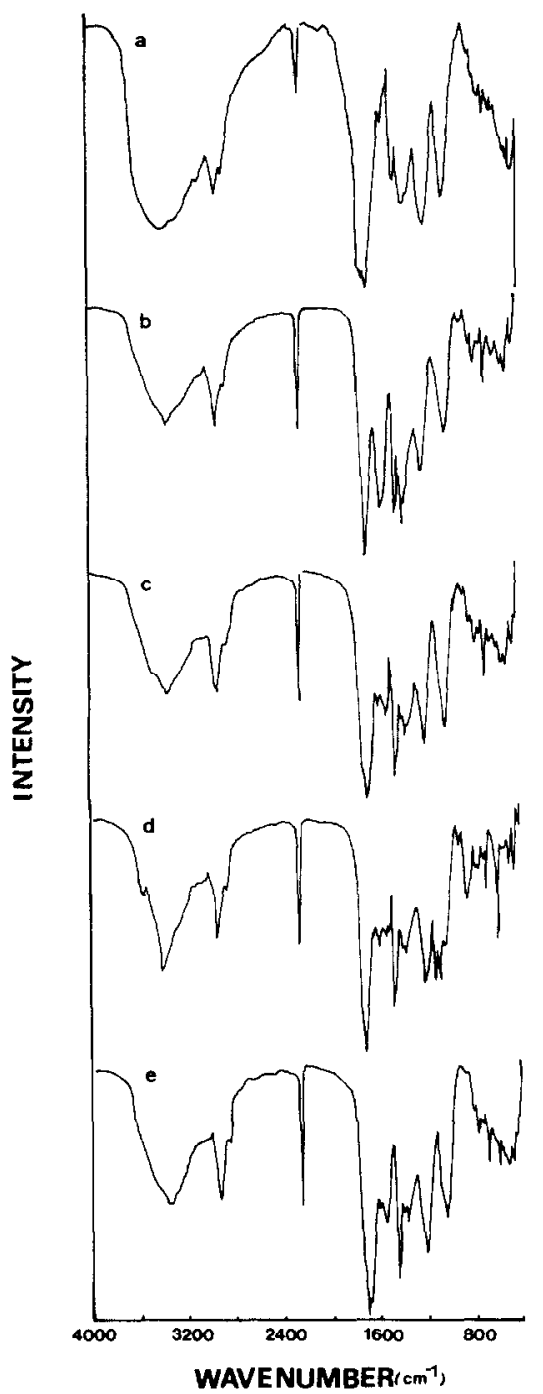

Fig. 4. Infrared spectra: (a) $N$-(hydroxymethyl)thioamide resin, (b) $\mathrm{Ag}-N$-(hydroxymethyl)thioamide resin complex, (c) $\mathrm{Co}-N$-(hydroxymethyl)thioamide resin complex, (d) $\mathrm{Cu}-$ $N$-(hydroxymethyl)thioamide resin complex, (e) $\mathrm{Mn}-N$ (hydroxymethyl)thioamide resin complex.

resin for lead ion was $0.45 \mathrm{mmol} \mathrm{g}^{-1}$. The functional group of the resin was also $0.45 \mathrm{mmol} \mathrm{g}^{-1}$. The results suggest that the lead ion forms a 1:1 complex with the $N$-(hydroxymethyl)thioamide resin.

The IR spectra of the metal complexes of the $N$-(hydroxymethyl)thioamide containing resin are shown in Fig. 4(b)-(e). All the absorption bands of the $-\mathrm{N}-\mathrm{C}=\mathrm{S}$ vibration $\left(1674,1527\right.$ and $\left.1356 \mathrm{~cm}^{-1}\right)$ and the $-\mathrm{C}=\mathrm{S}$ stretching ( 1203 and $544 \mathrm{~cm}^{-1}$ ) of the clielating resin (Fig. 4(a)) are shifted to shorter wavelength for the metal complexes. In the case of the metal complexes, furthermore, the $-\mathrm{OH}$ stretching absorption bands are also slightly different from that of the chelating resin (3463 and $1048 \mathrm{~cm}^{-1}$ ) and show absorption bands in a longer wavelength. All of 

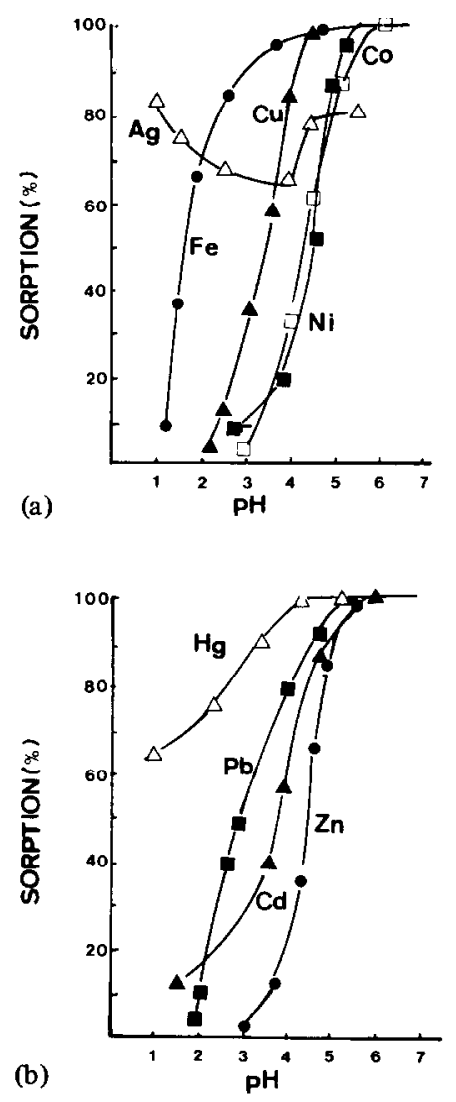

Fig. 5. Metal sorption as a function of $\mathrm{pH}$.

the above mentioned absorption peaks showed a distinct decrease in intensity for the metal complexes. This is believed to be due to the formation of a complex on the synthesized resin for all of the metal ions tested, the coordination sites for the complexation being on the sulfur and oxygen electron donor atom.

Figure 5(a) and (b) show the complex formation of the synthesized resin toward the metal ion in an excess of ligand versus $\mathrm{pH}$ variation. The order of affinity is $\mathrm{Hg}$ (II) $>\mathrm{Fe}$ (III) $>\mathrm{Pb}$ (II) $>\mathrm{Cu}$ (II) $>\mathrm{Cd}$ (II) $>\mathrm{Co}$ (II) $>\mathrm{Ni}$ (II) $\geqq \mathrm{Zn}$ (II) on the basis of $\mathrm{pH}_{1 / 2}$ which is $50 \%$ sorption of metal ion on the resin.

Figure 6(a) and (b) show the changes of $\log D$ as a function of $\mathrm{pH}$. Since the slope of most of the metal ions is positive and close to 1 , the results indicate that most of the metal ions tested form a 1:1 complex with the functional group of the resin. However, the behavior of mercury and silver is not the same as that of the previously mentioned metal ions. In a higher $\mathrm{pH}$ medium, the slope of both mercury and silver is positive, however, in a lower $\mathrm{pH}$ medium, the slope is negative. This is an interesting phenomenon and some relationship exists with the coloration development shown in Table 2. In a higher $\mathrm{pH}$ medium, the Agresin complex has a reddish orange color. In a lower
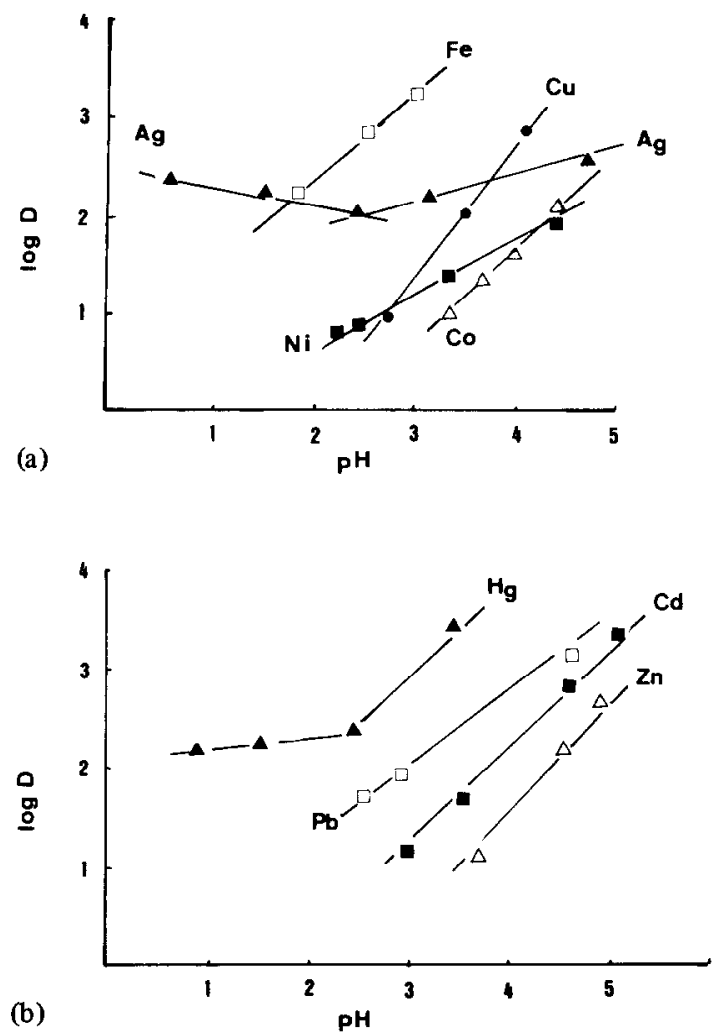

Fig. 6. $\log D$ vs. pH for metal ions on the $N$-(hydroxymethyl)thioamide resin. Amount of resin: $0.3 \mathrm{~g}$, amount of metal ion: $0.01 \mathrm{mmol}$, volume of solution: $25 \mathrm{ml}$.

$\mathrm{pH}$ medium, the $\mathrm{Ag}$-resin complex is white. Different color development indicates the different pattern of complex formation. In a lower $\mathrm{pH}$ medium, the white color formation may be due to the ion pair formation with the resin $\left(\mathrm{R}-\mathrm{CNHCH}_{2} \mathrm{OH}\right) \mathrm{H}^{+}$, and not the same<smiles>[As]=[As]</smiles>

mechanism as that in the higher $\mathrm{pH}$ medium.

All the cations in the resin-metal kinetics study showed high exchange rates. The rate of sorption of $\mathrm{Ag}(\mathrm{I}), \mathrm{Cd}(\mathrm{II}), \mathrm{Co}(\mathrm{II}), \mathrm{Cu}(\mathrm{II}), \mathrm{Fe}$ (III), $\mathrm{Hg}(\mathrm{II}), \mathrm{Ni}(\mathrm{II})$, $\mathrm{Pb}(\mathrm{II})$ and $\mathrm{Zn}(\mathrm{II})$ on $N$-(hydroxymethyl)thioamide resin is shown in Fig. 7(a)-(c). The time for 50\% recovery of the metal ions from this resin is rather short, except that for iron (requiring $7 \mathrm{~min}$ ). Therefore, the synthesized resin is quite suitable for chromatographic application.

\section{Formation Constants of Metal-Resin Complexes}

The stability of complexes formed in the resin phase is characterized by calculating their stability constants. Generally, the methods applied to study the stability constants of the chelating resin are the ligand competition method, the metal competition method, the proton competition method and the $\mathrm{pH}$ of the decomplexing method. Although the values of 


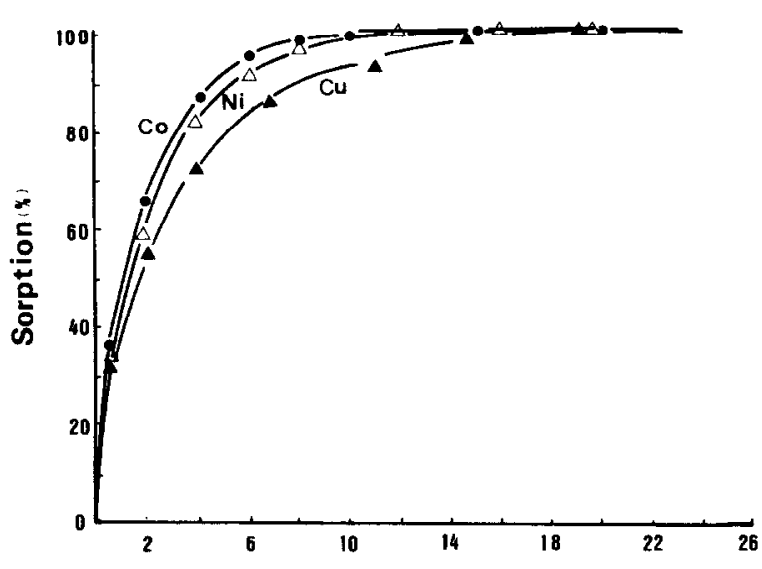

(a)

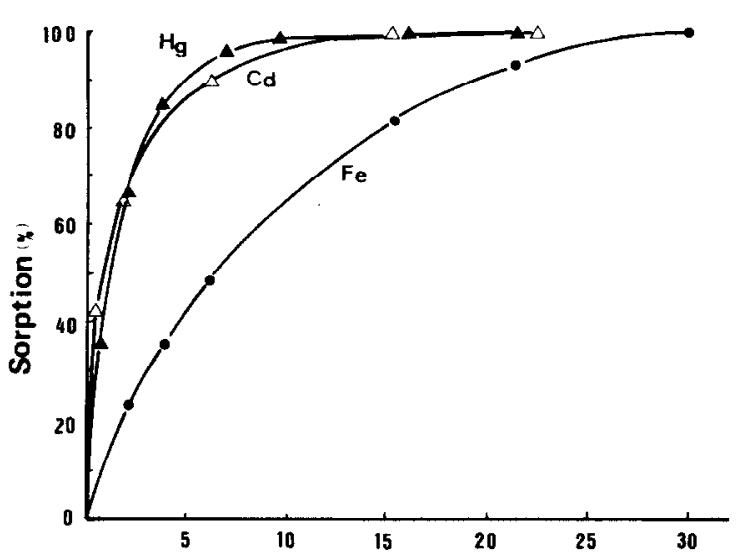

(b)

Time:min :

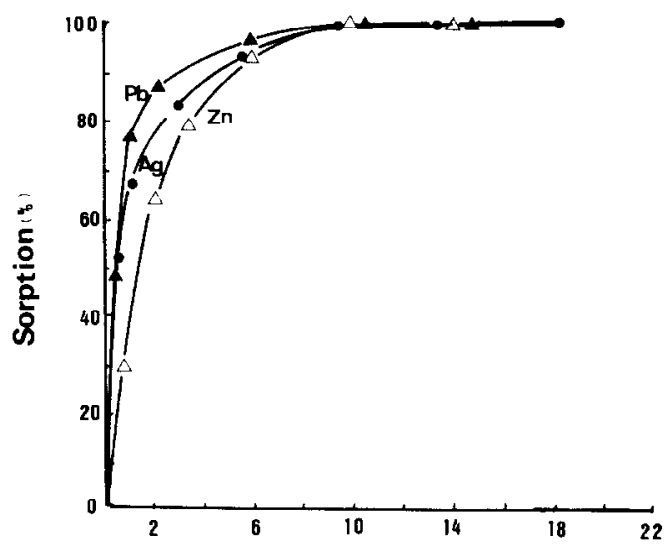

(c)

Time (min)

Fig. 7. Rate of sorption of metal ions on $N$-(hydroxymethyl)thioamide resin. Amount of resin: $0.3 \mathrm{~g}$, amount of metal ion: $0.01 \mathrm{mmol}$, volume of solution: $25 \mathrm{ml}$. (a) $\bullet \mathrm{Co}, \triangle \mathrm{Ni}$, $\Delta \mathrm{Cu}$; (b) $\bullet \mathrm{Fe}, \triangle \mathrm{Cd}, \Delta \mathrm{Hg}$; (c) $\bullet \mathrm{Ag}, \triangle \mathrm{Zn}, \Delta \mathrm{Pb}$.

the stability constants obtained are approximate, they are very useful in estimating the selectivity of chelating resins and their analytical potentialities. In this investigation, three methods were used to calculate the stability constants of the copper, silver and cadmium resin complexes, respectively.

(1) In the potentiometric determination of the complex formation constants of the metal ion $\mathrm{M}^{n+}$ with the synthesized resin, $\mathrm{AH}$, the following reaction was considered [17]

$\mathrm{M}^{n+}+i \mathrm{AH}=i \mathrm{H}^{+}+\mathrm{A} i \mathrm{M}^{(n-i)+}$

The complex formation equilibrium constants $\mathbf{B}_{i}$, were determined by a modification of Bjerrum's method.

$B_{i}=\frac{\left[\mathrm{A}_{i} \mathrm{M}^{(n-i)+}\right]\left[\mathrm{H}^{+}\right]^{i}}{[\mathrm{AH}]^{i}\left[\mathrm{M}^{n+}\right]}$

$\bar{n}=\frac{\sum_{i=1}^{N} i B_{i}\left(\frac{[\mathrm{AH}]}{\left[\mathrm{H}^{+}\right]}\right)^{i}}{1+\sum_{i=1}^{N} B_{i}\left(\frac{[\mathrm{AH}]}{\left[\mathrm{H}^{+}\right]}\right)^{i}}$

$B_{i}=\left(\prod_{i=1}^{i} k_{i}\right) K_{\mathrm{a}}^{i} \quad$ and $\quad \beta_{i}=\prod_{i=1}^{i} K_{i}$

where $K_{i}=\left[\mathrm{MA}_{i}\right] /\left[\mathrm{MA}_{i-1}\right][\mathrm{A}]$ is the stepwise constant for the $i$ th step, $\beta_{i}$ is the overall stability constant for the $i$ th complex, and $K_{\mathrm{a}}$ is the dissociation constant of the $N$-(hydroxymethyl)thioamide group in the resin. Equation (3) was solved graphically in the form $X P_{1}+Y P_{2}=1$.

$\frac{\bar{n}}{(1-\bar{n}) \frac{[\mathrm{AH}]}{\left[\mathrm{H}^{+}\right]}} \times \frac{1}{B_{1}}+\frac{(\bar{n}-2)[\mathrm{AH}]}{(1-\bar{n})\left[\mathrm{H}^{+}\right]} \times \frac{B_{2}}{B_{1}}=1$

Here, $B_{1}$ and $B_{1} / B_{2}$ could be calculated from the intercepts of the $X$ and $Y$ coordinate, respectively. Table 3 shows the result of the potentiometric determination of the formation constant of the copper-N-(hydroxymethyl)thioamide resin complex. By the graphic method mentioned above, the formation constant obtained for Cu-HMTA is $10^{3.90}$.

(2) In the ligand competition method, the procedure of Loewenschuss and Schmucker [18] is followed to determine the stability constant of the silver resin complex.

In this system, two competing complexation reactions take place

$$
\begin{array}{ll}
\mathrm{M}+\mathrm{Y}=\mathrm{MY} & K_{\mathrm{MY}}=\frac{[\mathrm{MY}]}{[\mathrm{M}][\mathrm{Y}]} \\
\mathrm{M}+\mathrm{R}=\mathrm{MR} & K_{\mathrm{MR}}=\frac{[\mathrm{MR}]}{[\mathrm{M}][\mathrm{R}]}
\end{array}
$$


TABLE 3. Potentiometric determination of the formation constant of the copper(II)- $N$-(hydroxymethyl)thioamide resin complex ${ }^{\mathbf{a}}$

\begin{tabular}{llllllllll}
\hline $\begin{array}{l}\text { Cu(II) added } \\
(\mathrm{mmol})\end{array}$ & $\begin{array}{l}\mathrm{pH} \text { of } \\
\text { solution }\end{array}$ & $\begin{array}{l}{[\mathrm{Cu}]} \\
(\mathrm{mmol})\end{array}$ & $\begin{array}{l}{[\overline{\mathrm{Cu}}]} \\
(\mathrm{mmol})\end{array}$ & $\begin{array}{l}{[\mathrm{AH}]} \\
(\mathrm{mmol})\end{array}$ & $\begin{array}{l}{\left[\mathrm{A}_{\mathrm{Cu}}\right]} \\
(\mathrm{mmol})\end{array}$ & $\bar{n}$ & $\frac{[\mathrm{AH}]}{\overline{\left[\mathrm{H}^{+}\right]}}$ & $\frac{\bar{n}}{(1-\bar{n}) \frac{[\mathrm{AH}]}{\left[\mathrm{H}^{+}\right]}}$ & $\frac{(\bar{n}-2)[\mathrm{AH}]}{(1-\bar{n})\left[\mathrm{H}^{+}\right]}$ \\
\hline 0.202 & 4.16 & 0.1524 & 0.0496 & 0.674 & 0.022 & 0.444 & 1094.76 & $7.294 \times 10^{-4}$ & $-3.063 \times 10^{3}$ \\
0.404 & 3.49 & 0.3420 & 0.0620 & 0.673 & 0.023 & 0.371 & 268.31 & $6.793 \times 10^{-4}$ & $-2.249 \times 10^{3}$ \\
0.505 & 3.63 & 0.4480 & 0.0570 & 0.670 & 0.026 & 0.456 & 844.76 & $9.922 \times 10^{-4}$ & $-2.398 \times 10^{3}$ \\
0.707 & 3.44 & 0.6450 & 0.0620 & 0.670 & 0.026 & 0.419 & 752.89 & $9.580 \times 10^{-4}$ & $-2.720 \times 10^{3}$ \\
0.909 & 3.21 & 0.8610 & 0.0400 & 0.673 & 0.023 & 0.479 & 689.75 & $1.330 \times 10^{-3}$ & $-1.833 \times 10^{3}$ \\
\hline
\end{tabular}

aVolume of solution: $25 \mathrm{ml}$, amount of resin: $0.3 \mathrm{~g}$.

TABLE 4. Equilibrium measurements for the silver-EDTA $-N$-(hydroxymethyl)thioamide resin system ${ }^{\mathrm{a}}$

\begin{tabular}{llllllll}
\hline $\begin{array}{l}\text { Ag taken } \\
(\mathrm{mmol})\end{array}$ & $\begin{array}{l}\text { EDTA taken } \\
(\mathrm{mmol})\end{array}$ & $\begin{array}{l}\text { Resin } \\
(\mathrm{g})\end{array}$ & $\begin{array}{l}\text { Ag/resin } \\
(\mathrm{mmol})\end{array}$ & $\begin{array}{l}\text { Ag-EDTA/soln } \\
(\mathrm{mmol})\end{array}$ & $\begin{array}{l}\text { EDTA/soln } \\
(\mathrm{mmol})\end{array}$ & $\log [\mathrm{R}]$ & $\log [\mathrm{MR}][\mathrm{Y}] /[\mathrm{MY}]$ \\
\hline 0.02 & 0.04 & 0.21 & 0.0189 & 0.0011 & 0.0389 & -1.15 & -0.013 \\
0.01 & 0.02 & 0.16 & 0.0098 & 0.0002 & 0.0198 & -1.23 & -0.175 \\
0.02 & 0.04 & 0.20 & 0.0187 & 0.0013 & 0.0388 & -1.17 & -0.035 \\
0.03 & 0.06 & 0.25 & 0.0289 & 0.0011 & 0.0490 & -1.10 & 0.188 \\
0.03 & 0.06 & 0.30 & 0.0289 & 0.0011 & 0.0589 & -1.10 & 0.416 \\
\hline
\end{tabular}

aVolume of solution: $25 \mathrm{ml}$, acidity of solution: $\mathrm{pH} 5.0$, maximum capacity of the resin: $0.43 \mathrm{mmol} / \mathrm{g}$, R: uncomplexed resin, MR: Ag/resin, MY: Ag-EDTA/solution, Y: EDTA/solution.

where $\mathrm{Y}$ is a competing ligand and $\mathrm{R}$ is the synthesized resin.

The overall reaction is

$$
\mathrm{MY}+\mathrm{R}=\mathrm{MR}+\mathrm{Y} \quad K_{\text {overall }}=\frac{[\mathrm{MR}][\mathrm{Y}]}{[\mathrm{MY}][\mathrm{R}]}=\frac{K_{\mathrm{MR}}}{K_{\mathrm{MY}}}
$$

Then the stability constant, $K_{\mathrm{MR}}$ of the metalresin complex can be obtained from the intercept of the graph by plotting $\log R$ against $\log [M R][Y] /$ [MY]. The equilibrium measurements for the silverEDTA $-N$-(hydroxymethyl)thioamide resin system are shown in Table 4 . The stability constant obtained for the silver-resin complex is $10^{4.54}$.

(3) The method of decomplexation $\mathrm{pH}$ [19] was used for determining the stability constant of the cadmium resin complex. The equation used was

$\log K_{\mathrm{MR}}=\log \beta_{j}^{\prime}-n \mathrm{DpH}$

where $\beta_{j}^{\prime}$ is the apparent cumulative protonation constant of the resin ligand and $n$ is the number of protons bound to the resin ligand. In order to calculate $K_{\mathrm{MR}}$, the protonation constant and the $\mathrm{DpH}$ values should be measured. Figure 6 shows the changes in $\mathrm{pH}$ and the metal content of the collected fractions as a function of the volume of the eluent. From this, the $\mathrm{DpH}$ value for $\mathrm{Cd}(\mathrm{II})$ was found to be
3.40. Since the protonation constant of the synthesized resin is $10^{6.56}$, the stability constant for the cadmium-resin complex is $10^{3.70}$.

The stability of complexes formed in the resin phase on the basis of the formation constants decreases in the order $\mathrm{Ag}(\mathrm{I})>\mathrm{Cu}$ (II) $>\mathrm{Cd}$ (II). The order is the same as that found on the basis of sorptive capacity. The difference in the stability of complexes formed in the resin phase during sorption is reflected in their selectivity with respect to individual elements. This serves as the basis for selective concentration and separation of elements.

\section{Acknowledgement}

Financial support of this work by the National Science Council of the Republic of China is gratefully acknowledged.

\section{References}

1 A. K. Majumdar, N-Benzoylphenylhydroxylamine and its Analogues, Pergamon, New York, 1972.

2 J. Stary, The Solvent Extraction of Metal Chelates, Pergamon, New York, 1964 
3 H. L. Yale, Chem. Rev., 33 (1943) 209.

4 H. Metzger, Herstellung von Hydroxamsäuren und deren Derivaten, in Eu. Müller (ed.), Houben-Weyl, Methoden der Organischen Chemie, Vol. X/4, Georg Thieme, Stuttgart, 4th edn., 1968.

5 J. B. Bapat, D. S. C. Black and R. F. C. Brown, $A d v$. Heterocycl. Chem., $10(1969) 199$.

6 K. A. Jensen, Q. Buchardt and C. Christophersen, Acta Chem. Scand, 21 (1967) 1936.

7 S. Mizukami and K. Nagata, Chem. Pharm. Bull., 14 (1966) 1249.

8 K. Nagata and S. Mizukami, Chem. Pharm. Bull., 14 (1966) 1255.

9 K. Nagata and S. Mizukami, Chem. Pharm. Bull., 14 (1966) 1263.

10 C. Y. Liu and P. J. Sun, Fresenius L. Anal. Chem., 325 (1986) 553
11 C. Y. Liu, J. D. Fan and C. B. Liu, Proc. Natl. Sci. Connc. $R O C(A), 10$ (1986) 352.

12 C. Y. Liu and P. J. Sun, Anal. Chim. Acta, 132 (1981) 187.

13 J. Zabicky, The Chemistry of Amides, London Interscience, London, 1970

14 Ö. Szabadka, Talanta, 29 (1982) 177

15 S. Mizukami and K. Nagata, Coord. Chem. Rev., 3 (1968) 267.

16 K. A. Jensen and P. H. Nielsen, Acta Chem. Scand, 20 (1966) 597.

17 Y. A. Zolotarev, A. A. Kurganov and V. A. Davankov, Talanta, 25 (1978) 493.

$18 \mathrm{H}$. Loewenschuss and G. Schmuckler, Talanta, 11 (1964) 1399.

19 R. Hering, Chelatbildende Ionenaustauscher, Akademie Verlag, Berlin, 1967. 